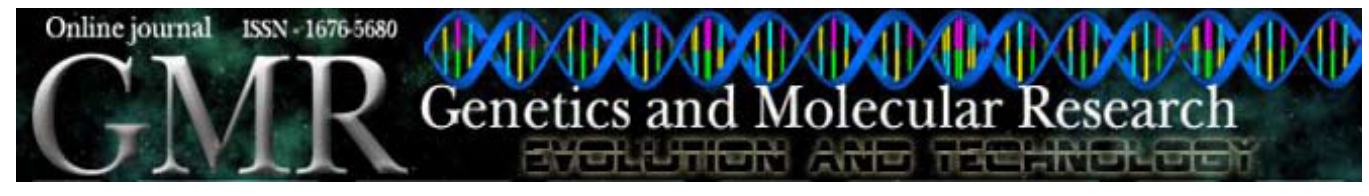

\title{
Phylogenetic relationships of Malaysian monkeys, Cercopithecidae, based on mitochondrial cytochrome c sequences
}

\author{
B.M. Md-Zain ${ }^{1}$, M. Mohamad ${ }^{1}$, M.A. Ernie-Muneerah ${ }^{1}$, A. Ampeng ${ }^{1,4}$, \\ A. Jasmi ${ }^{2}$, M. Lakim ${ }^{3}$ and M.C. Mahani ${ }^{1}$ \\ ${ }^{1}$ School of Environmental and Natural Resource Sciences, \\ Faculty of Science and Technology, Universiti Kebangsaan Malaysia, \\ Bangi, Selangor, Malaysia \\ ${ }^{2}$ Department of Wildlife and National Parks, Peninsular Malaysia, \\ Kuala Lumpur, Malaysia \\ ${ }^{3}$ The Board of Trustees of Sabah Parks, Kinabalu Park, Kota Kinabalu, \\ Sabah, Malaysia \\ ${ }^{4}$ Sarawak Forestry Department, Kuching, Sarawak, Malaysia \\ Corresponding author: B.M. Md-Zain \\ Email: abgbadd@ukm.my / abgbadd1966@yahoo.com
}

Genet. Mol. Res. 9 (4): 1987-1996 (2010)

Received June 2, 2010

Accepted July 20, 2010

Published October 5, 2010

DOI 10.4238/vol9-4gmr942

ABSTRACT. Mitochondrial DNA cytochrome c oxidase II (COII) gene
sequences of Malaysian Cercopithecidae were examined to ascertain
their phylogenetic relationships. Colobinae were represented by the
genera Presbytis, Trachypithecus and Nasalis, while the genus Macaca
represented Cercopithecinae. DNA amplification and sequencing of the
COII gene was performed on 16 samples. Symphalangus syndactylus
(Hylobatidae) was used as the outgroup. Data were analyzed using
both character (maximum parsimony) and distance (neighbor-joining)
methods. Tree topologies indicated that Colobinae and Cercopithecinae
have their own distinct monophyletic clade. This result was well
supported by bootstrap values and genetic distances derived from the
Kimura-2-parameter algorithm. Separation of Macaca nemestrina from
M. fascicularis was also well supported by bootstrap values. In addition, 
tree topologies indicate a good resolution of the Colobinae phylogenetic relationships at the intergeneric level, but with low bootstrap support. The position of Nasalis remained problematic in both trees. Overall, COII is a good gene candidate for portraying the phylogenetic relationships of Malaysian primates at the inter- and intra-subfamily levels.

Key words: Malaysian primates; COII gene; Molecular phylogeny; Cercopithecinae; Colobinae

\section{INTRODUCTION}

Malaysian cercopithecids consist of two groups, the cercopithecine (subfamily Cercopithecinae) and colobine (subfamily Colobinae) (Md-Zain, 2001). Members of these subfamilies live sympatrically but are separated by their life styles, either arboreal or terrestrial, and their diets (Marsh and Wilson, 1981). Macaca, the only genus in cercopithecine representing the omnivorous group, includes three species: Macaca fascicularis, M. nemestrina and M. arctoides, whereas the wholly Malaysian vegetarian colobines, known as langurs or leaf monkeys, are represented by three genera: Presbytis, Trachypithecus and Nasalis (Oates et al., 1994). Trachypithecus is represented by two species (T. obscurus and T. cristatus) while Nasalis by a single species, Nasalis larvatus (Md-Zain et al., 2008). The number of species in the genus Presbytis varies according to primatologist lists (Groves, 2001; Brandon-Jones et al., 2004; Md-Zain et al., 2008). P. hosei, P. rubicunda, and P. frontata remain as the valid species. However, various classifications have been made on the P. melalophos groups involving femoralis siamensis, robinsoni, chrysomelas, and cruciger. Many primatologists still favor the retention of P. melalophos as a single polytypic species with numerous subspecies (Oates et al., 1994; Md-Zain, 2001). However, some subspecies have been assigned at the species level (Groves, 2001; Brandon-Jones et al., 2004). The differences in the classification of these species may cause difficulty in conservation efforts.

Cytochrome c oxidase subunit II (COII) is the third largest component of the cytochrome c oxidase complex. The evolution rates of the COII gene in both nucleotide and amino acid sequences are believed to be significantly higher than for COI and COIII (Ramharack and Deeley, 1987). Analysis of sequence data based on the COII gene has been successfully conducted with mammals (Adkins et al., 1996; Shevchuk and Allard, 2001). However, in many phylogenetic relationship studies, other genes of mitochondrial DNA are still favored as gene candidates (Shahrom et al., 2005; Khan et al., 2008; Lim et al., 2010; Md-Zain et al., 2010). In primate evolutionary studies, several COII gene data analyses have focused on hominoids and the New World Monkeys (Ruvolo et al., 1991, 1993). For New World Monkeys, the sequence of the COII gene has been studied on Platyrrhini including both Atelidae and Cebidae families (Ascunce et al., 2002): owl monkeys, genus Aotus (Ashley and Vaughn, 1995); spider monkeys, genus Ateles (Collins and Dubach, 2000) and marmoset species group (Sena et al., 2002).

For Old World Monkeys, molecular phylogeny studies have been focusing mainly on Africa. For example, the phylogenetic studies of the tribe Papionini, composed of baboons, mandrills, drills, and mangabeys were conducted on the African continent (Ruvolo et al., 1991; Disotell et al., 1992; Harris, 2000). Phylogenetic inference using COII gene in the Asian region remains less pronounced than in the African region. These studies include the macaques 
(Ramharack and Deeley, 1987) and leaf monkeys (Ernie-Muneerah et al., 2005). These various molecular studies indicate the potential of the COII gene as a gene candidate in studying molecular evolution in primates.

Conservation efforts are compulsory, but conservation management plans are difficult to set up if the systematic relationships among species remain unclear. Previously, variable primate classifications have been proposed especially for Presbytis and Trachypithecus (Oates et al., 1994; Brandon-Jones et al., 2004; Md-Zain et al., 2008). In addition, both colobines and cercopithecines have been distinguished by certain features (Oates et al., 1994; Groves, 2001). Unfortunately, these classifications are based mostly on morphological, behavioral, ecological, and biogeographical information, and not genetic data (Brandon-Jones et al., 2004). The application of phylogenetics is important to improve the systematic classification of Malaysian primates. Constructing the phylogenetic tree that shows the relationship between Malaysian primate species, particularly Cercopithecinae and Colobinae subfamilies, is thus vital.

\section{MATERIAL AND METHODS}

\section{Sample and genomic DNA extraction}

Tissue samples of different Malaysian cercopithecoids used in this study are listed in Table 1. Genetic samples were obtained from several institutions such as the Department of Wildlife and National Parks, Sabah Parks, and the Sarawak Forestry Department. DNA was extracted from the tissue samples using the GENE ALL Tissue and Tissue (Plus!) SV mini-extraction kit.

\begin{tabular}{|c|c|c|c|}
\hline No. & Code & Species & Locality \\
\hline 1 & BM29 & P. $m$. robinsoni & Selama, Perak \\
\hline 2 & BM40 & P. m. femoralis & Mersing, Johor \\
\hline 3 & BM67 & P. hosei & Tawau, Sabah \\
\hline 4 & BM70 & P. hosei & Danum Valley, Sabah \\
\hline 5 & BM08 & T. obscurus & Sik, Kedah \\
\hline 6 & BM09 & T. obscurus & Changloon, Kedah \\
\hline 8 & BM19 & T. obscurus & Tupah, Kedah \\
\hline 9 & AA102 & N. larvatus & Sarawak \\
\hline 10 & SP156 & M. nemestrina & Kinabalu Park, Sabah \\
\hline 11 & SP206 & M. nemestrina & Kinabalu Park, Sabah \\
\hline 12 & MF01 & M. fascicularis & Pulau Sapi, Sabah \\
\hline 13 & MF03 & M. fascicularis & Pulau Sapi, Sabah \\
\hline 14 & MF05 & M. fascicularis & Pulau Sapi, Sabah \\
\hline 15 & MF06 & M. fascicularis & Pulau Sapi, Sabah \\
\hline 16 & MF07 & M. fascicularis & Pulau Sapi, Sabah \\
\hline
\end{tabular}

\section{Polymerase chain reaction}

COII of the mtDNA gene was amplified by polymerase chain reaction (PCR) using the Perkin Elmer GeneAmp ${ }^{\circledR}$ PCR System 2400. Amplification was performed using $50 \mu \mathrm{L}$ total volume per reaction with $50 \mathrm{ng}(5 \mu \mathrm{L})$ DNA template, 0.2 pmol $(0.5 \mu \mathrm{L})$ primer, $3.0 \mathrm{mM}$ $(6.0 \mu \mathrm{L}) \mathrm{MgCl}_{2}, 0.2 \mathrm{mM}(1.0 \mu \mathrm{L}) \mathrm{dNTP}$ mix, $1 \mathrm{X}(6.0 \mu \mathrm{L})$ PCR buffer, and $2.5 \mathrm{U}(0.5 \mu \mathrm{L}) \mathrm{Taq}$ 
Polymerase. Two oligonucleotide primers L7553 (5'-AACCATTTCATAACTTTGTCAA-3') and H8320 (5'-CTCTTAATCTTTAACTTAAAAG-3') based on Adkins and Honeycutt (1994) were used. The temperature profile for 35 amplification cycles was pre-denaturation $\left(94.0^{\circ} \mathrm{C}\right.$ for $\left.3 \mathrm{~min}\right)$, denaturation $\left(94^{\circ} \mathrm{C}\right.$ for $\left.60 \mathrm{~s}\right)$, annealing $\left(51-55^{\circ} \mathrm{C}\right.$ for $\left.60 \mathrm{~s}\right)$, extension $\left(72.0^{\circ} \mathrm{C}\right.$ for $\left.70 \mathrm{~s}\right)$, and post-extension $\left(72.0^{\circ} \mathrm{C}\right.$ for $\left.9 \mathrm{~min}\right)$. Amplified products were purified using the QIAquick gel purification kit protocol (QIAGEN) and visualized using 1.5\% agarose gel electrophoresis. The purified DNA was then stored at $-20^{\circ} \mathrm{C}$ and sent for DNA sequencing at First Base (First BASE Laboratories Sdn Bhd, Malaysia).

\section{Data analysis}

DNA sequences were aligned using CLUSTALW. Sequence data were analyzed using both character and distance methods in PAUP version 4.0 (Swofford, 2002). Symphalangus syndactylus (M580071) from Genbank was employed as the outgroup. Maximum parsimony (MP) and neighbor joining (NJ) analysis were conducted. Trees were obtained by heuristic or branch and bound searches. The data were also subjected to bootstrap analysis with 2000 replications in order to estimate the strength of support for each clade. Neighbor-joining analysis based on the distance measure of Kimura-2-parameter was obtained, as were branch lengths for the most parsimonious MP tree using the "describe tree" option of PAUP. Homoplasy was quantified using the consistency index (CI) and the homoplasy index (HI).

\section{RESULTS}

\section{PCR products}

For macaque and leaf monkey samples, the estimated DNA fragment size of the amplified COII gene was around 850 bp. Sample BM29 had the brightest DNA band indicating the highest concentration of PCR product. Other samples produced relatively faint DNA bands or lower concentrations of PCR products (Figure 1). Leaf monkey samples were succesfully amplified at $55^{\circ} \mathrm{C}$ while macaques needed annealing temperatures ranging from $51^{\circ}$ to $55^{\circ} \mathrm{C}$.

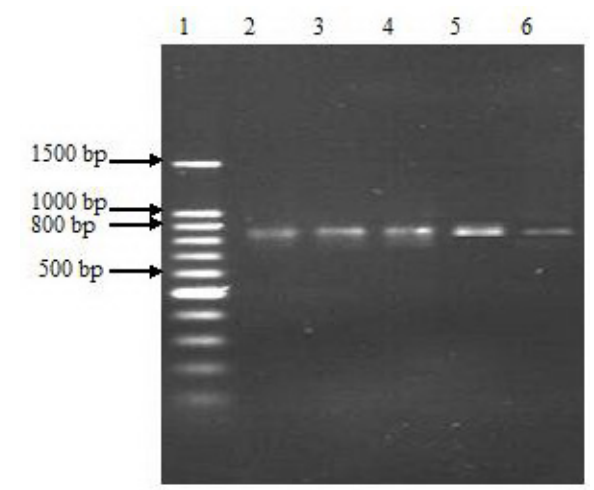

Figure 1. Amplification products of the COII gene for leaf monkeys. Lane 1=100-bp ladder; lane 2= BM25; lane $3=\mathrm{BM} 0$; lane $4=\mathrm{BM} 1$; lane $5=\mathrm{BM} 29$; lane $6=\mathrm{BM} 1$. 


\section{Phylogenetic inference}

MP analysis was conducted using a heuristic search in PAUP version 4.0 (Swofford, 2002). Table 2 shows variations along the sequences across taxa. Findings showed that $61.3 \%$ of the total characters examined were constant characters, $9.57 \%$ characters were parsimony uninformative and $29.13 \%$ characters were parsimony informative. Our MP analysis yielded a single bootstrap tree (length $=123, \mathrm{CI}=0.8049, \mathrm{HI}=0.1095)$ (Figure 2). Two distinct monophyletic clades are clearly shown on the phylogeny tree of Malaysian Cercopithecidae. These Cercopithecinae and Colobinae clades were fully supported by high bootstrap values, 90 and $100 \%$, respectively. Within Cercopithecinae, Macaca nemestrina (SP156 and SP206) formed a clade with 100\% bootstrap support. M. fascicularis, consisting of Borneo samples (MF01, MF05, MF06, MF07, and SP03), also formed a clade, with $99 \%$ bootstrap value support. In Colobinae, the node was resolved where leaf monkey samples clustered according to genus. P. m. robinsoni (BM29), P. m. femoralis (BM40) and P. hosei (BM67 and BM70) formed the Presbytis clade while all T. obscurus samples (BM08, BM09, and BM19) clustered in the Trachypithecus clade. Nasalis, which was only represented by a single sample (AA02), joined together in the Colobinae clade with its phylogenetic position remaining unclear. Although the genus node was resolved in the Colobinae clade, the supports on each clade were not high, 57 and 58\% bootstrap values in Presbytis and Trachypithecus, respectively.

\begin{tabular}{|c|c|c|c|c|c|c|}
\hline \multirow[t]{2}{*}{ Locus } & \multicolumn{2}{|c|}{ Nuclear gene } & \multicolumn{4}{|c|}{ Mitochondrial gene } \\
\hline & $\mathrm{SRY}^{\mathrm{a}}$ & IRBP $^{a}$ & ND3-ND4 ${ }^{\mathrm{a}}$ & Cyt $b^{\mathrm{b}}$ & $12 \mathrm{~S}$ rRNA ${ }^{\mathrm{b}}$ & $\mathrm{COII}^{\mathrm{c}}$ \\
\hline Total characters examined & 3060 & 1613 & 2080 & 388 & 371 & 230 \\
\hline Constant characters & 2767 & 1518 & 1276 & 225 & 283 & 141 \\
\hline Parsimony-uninformative characters & 111 & 33 & 154 & 6 & 7 & 22 \\
\hline Parsimony-informative characters & 180 & 62 & 650 & 157 & 81 & 67 \\
\hline$\%$ Parsimony-informative characters & 6.0 & 3.8 & 31.5 & 40.5 & 21.8 & 29.1 \\
\hline Tree length & 334 & 109 & 1773 & 79 & 133 & 123 \\
\hline
\end{tabular}

${ }^{\mathrm{a}}$ Md-Zain, 2001; Md-Zain et al., 2008. ${ }^{\mathrm{b}}$ Vun, 2007. ${ }^{\mathrm{c}}$ This study.

The NJ tree is concordant with the MP tree as it shares a relatively similar tree topology of phylogenetic relationships (Figure 3). Cercopithecinae and Colobinae subfamilies formed their distinct monophyletic clades at 87 and $100 \%$ of bootstrap support, respectively. Both $M$. nemestrina and M. fascicularis were highly defined as distinct species with a $100 \%$ bootstrap value. Although the position of Nasalis in the NJ tree is problematic, the leaf monkey clade was almost resolved by NJ analyses by medium bootstrap value support.

An average genetic distance was generated using the Kimura-2-parameter algorithm. The genetic distance between and among genera is summarized in Table 3. The intra-generic averages of genetic distance for Presbytis, Trachypithecus and Macaca are 1.40, 1.33, and $8.76 \%$, respectively. In the leaf monkeys, the average genetic distances between Presbytis and Trachypithecus; Presbytis and Nasalis, and Trachypithecus and Nasalis are 3.42, 5.36, and $5.47 \%$, respectively. This result indicates that the intra-generic genetic distance of each genus is less than that in the inter-generic level. The genetic distances between Colobinae and Cercopithecinae are quite high: Presbytis (27.79\%), Trachypithecus (27.70\%) and Nasalis (31.87\%). In macaques, the average intra-species genetic distances in M. fascicularis and $M$. nemestrina are 1.45 and $0.44 \%$, respectively; while the average genetic distance between $M$. 


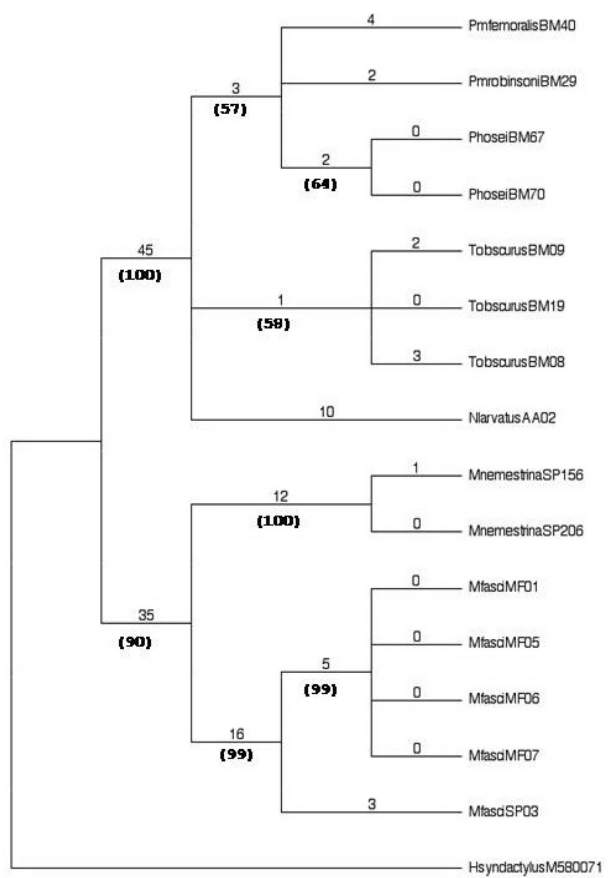

Figure 2. Maximum parsimony tree of partial COII mtDNA gene sequences. Numbers under branches (in parentheses) are the percentage of bootstrap values at 2000 replicates while numbers above branches are the branch lengths.

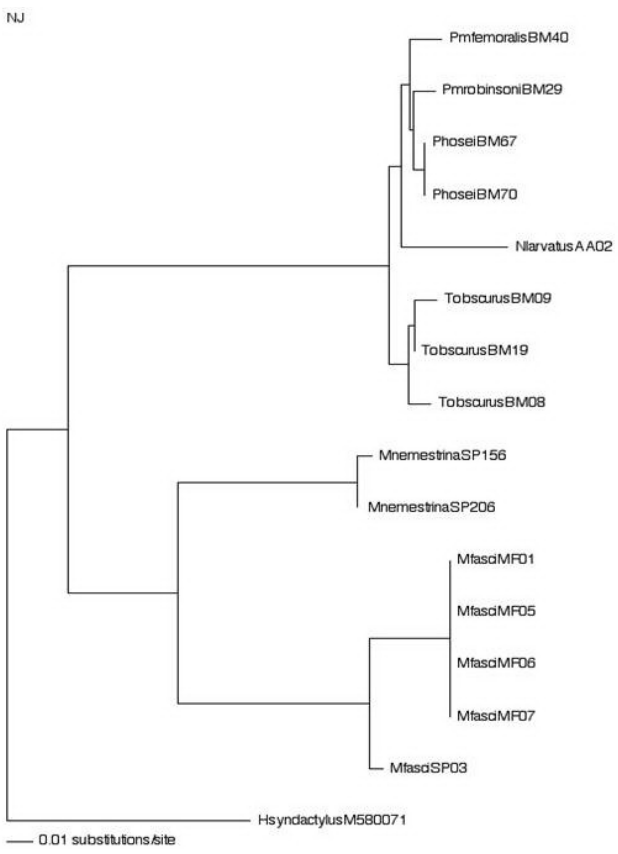

Figure 3. Neighbor-joining phylogram of partial COII mtDNA sequences. 


\begin{tabular}{|c|c|c|c|c|}
\hline & Presbytis & Trachypithecus & Nasalis & $\overline{\text { Macaca }}$ \\
\hline Presbytis & 1.404 & - & & \\
\hline Trachypithecus & 3.421 & 1.326 & - & \\
\hline Nasalis & 5.357 & 5.468 & - & - \\
\hline Macaca & 27.785 & 27.704 & 31.869 & 8.755 \\
\hline
\end{tabular}

Table 4. Average genetic distance among and between Malaysian macaque species using the Kimura-2-parameter.

\begin{tabular}{lcc}
\hline & Macaca fascicularis & Macaca nemestrina \\
\hline Macaca fascicularis & 1.448 & - \\
Macaca nemestrina & 16.893 & 0.44 \\
\hline
\end{tabular}

fascicularis and M. nemestrina is $16.90 \%$ (Table 4).

\section{DISCUSSION}

In order to obtain the best PCR conditions, optimization of annealing temperatures was carried out in the range of $51-55^{\circ} \mathrm{C}$ for macaque samples. All the annealing temperature trials produced the same results; the best based on band brightness was recorded at $51{ }^{\circ} \mathrm{C}$. This finding supports a previous study (Table 5) on the same gene and same subfamily Cercopithecinae in the tribe Papionini (Disotell et al., 1992), whereas for the PCR conditions of gorilla, siamang and macaques, as described by Ruvolo et al. (1991), the annealing process required $50-57^{\circ} \mathrm{C}$ for 1 min. A study by Ernie-Muneerah et al. (2005) on leaf monkeys required an annealing temperature of $54-55^{\circ} \mathrm{C}(1 \mathrm{~min})$. This is in line with the range of annealing temperatures used for the leaf monkeys in this study. Md-Zain et al. (2004) stated that the right mixture of PCR components is important to obtain positive results with good and clear bands. The right volume of DNA template used, annealing temperature, extension time, and cycle numbers are all equally important.

\begin{tabular}{lcc} 
Table 5. Comparison of annealing temperatures for the COII gene within the order Primates. & \\
\hline Primates & Annealing temperature & References \\
\hline Old World Monkey Tribe Papionini & $51^{\circ}-55^{\circ} \mathrm{C} 1 \mathrm{~min}$ & Disotell et al., 1992 \\
Gorilla, Siamang and Macaques & $50^{\circ}-57^{\circ} \mathrm{C} 1 \mathrm{~min}$ & Ruvolo et al., 1991 \\
Apes & $50^{\circ}-57^{\circ} \mathrm{C} 1 \mathrm{~min}$ & Ruvolo et al., 1993 \\
Malaysian leaf monkeys & $54^{\circ}-55^{\circ} \mathrm{C} 1 \mathrm{~min}$ & Ernie et al., 2005 \\
Malaysian Cercopithecidae & $51^{\circ}-55^{\circ} \mathrm{C} 1 \mathrm{~min}$ & This study \\
\hline
\end{tabular}

The percentage of informative characters in the COII gene is compared with several loci of mtDNA and nuclear genes from previous studies (Table 2). The differences in percentage between mtDNA and the nuclear genes signify that the mtDNA region has evolved more rapidly compared to the nuclear regions of cercopithecids. The slower evolution of the nuclear regions is evident in the lower percentage of informative characters they possess. The ability of mtDNA to resolve phylogenetic relationships among the cercopithecids (Karanth et al., 2008; Osterholz et al., 2008; Roos et al., 2008) and other primates has been discussed by several researchers (Shahrom et al., 2005; Lim et al., 2010; Md-Zain et al., 2010). Thus, based on the reasonable percentage of informative characters, COII can also be regarded as a good locus candidate to be used in portraying the phylogenetic relationships 
of Malaysian Cercopithecidae.

Partial COII mtDNA gene sequences used in this study seem to be effective in determining the phylogenetic relationships between the two subfamilies. This is because both MP and $\mathrm{NJ}$ tree topology showed very clear distinction between Cercopithecinae and Colobinae as they formed their own highly supported monophyletic clade. Furthermore, the average genetic distance is proof of the distinction of these subfamilies as their values fall into the range of 27 to $32 \%$. This result supports previous studies on mitochondrial and nuclear genes (Page et al., 1999; Chatterjee et al., 2009). In macaques, the node is solved in MP and NJ tree as two highly supported monophyletic clades are formed, representing the species M. fascicularis and $M$. nemestrina. High genetic distance also supports their distinction by which both species come from different macaque groups, specifically $M$. fascicularis from the fascicularis group and M. nemestrina from the silenus-sylvanus group (Groves, 2001). Our results are congruent with other previous results based on DNA data (Chatterjee et al., 2009; Li et al., 2009). Macaca, the single genus of Malaysian Cercopithecinae, is clearly divided into two distinct groups representing the macaque species, $M$. nemestrina and $M$. fascicularis. This result is supported by high bootstrap values in both MP and NJ trees and by the average genetic distance.

The distinction of three genera of leaf monkeys (Colobinae), Presbytis, Trachypithecus, and Nasalis, is not as clear as the clade resolved by partial COII mtDNA gene sequences and is not highly supported by bootstrap values in MP and NJ tree. At the inter-generic level of leaf monkeys (Colobinae), the partial COII gene nucleotide sequences used resolved the node joining Presbytis, Trachypithecus and Nasalis but has low bootstrap support. In this case, Presbytis and Trachypithecus formed their own monophyletic clade distinct from each other but with low bootstrap values. Many morphologists and ecologists do not agree on a common delimitation of species within the Presbytis group (Groves, 1989; Brandon-Jones, 1995). Formerly, Trachypithecus was grouped into Presbytis (Peng et al., 1988; Li, 1993). However, the separation of Trachypithecus from Presbytis has been adopted by several other researchers (Oates et al., 1994; Brandon-Jones et al., 2004) based on ecological and morphological data. These findings are further validated by Md-Zain et al. (2008) and data based on mitochondrial DNA sequences in this study. Meanwhile the position of Nasalis is problematic for both MP and NJ trees. This problem is due to the limited number of Nasalis samples obtained.

The separation of the two subfamilies of Malaysian Cercopithecidae (Cercopithecinae and Colobinae) is supported by MP and NJ analysis as well as with the high average percentage of genetic distance among them based on the Kimura-2-parameter distance matrix method. Overall, partial COII gene nucleotide sequences utilized in this study are effective in clarifying the phylogenetic relationships between and within the Cercopithecinae and Colobinae subfamilies. For further studies, more samples should be used especially for the leaf monkeys. This is important to generate more reliable results on the molecular phylogeny of Malaysian Cercopithecidae.

\section{ACKNOWLEDGMENTS}

The authors thank the members of the Cytogenetics Laboratory (Dr. Ang Khai Chung, Vun Vui Fui, Lim Lee Sim), Faculty of Science and Technology, Universiti Kebangsaan Malaysia. We are deeply indebted to several institutions that provided us with necessary facilities and assistance with tissue sample collection including UKM, Department of Wildlife and 
National Parks, Sarawak Forestry Department and Sabah Parks. We wish to thank Farhana Shukor, Sri Harminda Hartantyo and anonymous reviewers for their comments on the manuscript. Research supported by grants UKM J/1/98, IRPA 0802020019 EA301 and UKMKRIB-16/2008.

\section{REFERENCES}

Adkins RM and Honeycutt RL (1994). Evolution of the primate cytochrome c oxidase subunit II gene. J. Mol. Evol. 38: 215-231.

Adkins RM, Honeycutt RL and Disotell TR (1996). Evolution of eutherian cytochrome c oxidase subunit II: heterogeneous rates of protein evolution and altered interaction with cytochrome c. Mol. Biol. Evol. 13: 1393-1404.

Ascunce MS, Hasson E and Mudry MD (2002). Description of the cytochrome c oxidase subunit II gene in some genera of New World monkeys (Primates, Platyrrhini). Genetica 114: 253-267.

Ashley MV and Vaughn JL (1995). Owl monkeys (Aotus) are highly divergent in mitochondrial cytochrome c oxidase (COII) sequences. Int. J. Primatol. 16: 793-806.

Brandon-Jones D (1995). A revision of the Asian pied leaf monkeys (Mammalia: Cercopithecidae: Superspecies Semnopithecus auratus), with a description of a new subspecies. Raffles Bull. Zool. 43: 3-43.

Brandon-Jones D, Eudey AA, Geissmann T, Groves CP, et al. (2004). Asian primate classification. Int. J. Primatol. 25: 97-164.

Chatterjee HJ, Ho SY, Barnes I and Groves C (2009). Estimating the phylogeny and divergence times of primates using a supermatrix approach. BMC Evol. Biol. 9: 259.

Collins AC and Dubach MJ (2000). Phylogenetic relationships of Spider Monkeys (Ateles) based on mitochondrial DNA variation. Int. J. Primatol. 21: 381-420.

Disotell TR, Honeycutt RL and Ruvolo M (1992). Mitochondrial DNA phylogeny of the Old-World monkey tribe Papionini. Mol. Biol. Evol. 9: 1-13.

Ernie-Muneerah MA, Ahmad N, Ang KC, Ampeng A, et al. (2005). Polymerase chain reaction (PCR) optimization for COIIrRNA gene fragment of Malaysian Leaf Monkeys. J. Wildl. Parks 22: 71-76.

Groves CP (1989). A Theory of Human and Primate Evolution. Clarendon Press, Oxford.

Groves CP (2001). Primate Taxonomy. Smithsonian Institution Press, Washington.

Harris EE (2000). Molecular systematics of the old world monkey tribe Papionini: analysis of the total available genetic sequences. J. Hum. Evol. 38: 235-256.

Karanth KP, Singh L, Collura RV and Stewart CB (2008). Molecular phylogeny and biogeography of langurs and leaf monkeys of South Asia (Primates: Colobinae). Mol. Phylogenet. Evol. 46: 683-694.

Khan HA, Arif IA, Al Homaidan AA and Al Farhan AH (2008). Application of 16S rRNA, cytochrome b and control region sequences for understanding the phylogenetic relationships in Oryx species. Genet. Mol. Res. 7: 1392-1397.

Li J, Han K, Xing J, Kim HS, et al. (2009). Phylogeny of the macaques (Cercopithecidae: Macaca) based on Alu elements. Gene 448: 242-249.

Li ZY (1993). Preliminary investigation of the habitats of Presbytis francoisi and Presbytis leucocephalus, with notes on the activity pattern of Presbytis leucocephalus. Folia Primatol. 60: 83-93.

Lim LS, Ang KC, Mahani MC, Shahrom AW, et al. (2010). Mitochondrial DNA polymorphism and phylogenetic relationships of proto malays in Peninsular Malaysia. J. Biol. Sci. 10: 71-83.

Marsh CW and Wilson WL (1981). A Survey of Primates in Peninsular Malaysian Forest. Final Report for the Malaysian Primates Research Programme Universiti Kebangsaan Malaysia and University of Cambridge, United Kingdom.

Md-Zain BM (2001). Molecular Systematics of the Genus Presbytis. Doctoral thesis, Columbia University, New York.

Md-Zain BM, Vun VF, Azman S and Zaidi MI (2004). Polymerase chain reaction (PCR) optimization for 16S rRNA gene fragment of cicadas (Homoptera: Cicadoidea) from Peninsular Malaysia. Serangga 9: 171-183.

Md-Zain BM, Morales JC, Hassan MN, Abdul J, et al. (2008). Is Presbytis a distinct monophyletic genus: inferences from mitochondrial DNA sequences. Asian Primates $J .1: 26-36$.

Md-Zain BM, Lee SJ, Lakim M, Ampeng A, et al. (2010). Phylogenetic position of Tarsius bancanus based on partial cytochrome b DNA sequences. J. Biol. Sci. 10: 348-354.

Oates JF, Delson E and Delson E (1994). The Diversity of Living Colobines. In: Colobine Monkey: Their Ecology, Behavior and Evolution (Davies AG and Oates JF, eds.). Cambridge University Press, Cambridge, 45-73.

Osterholz M, Walter L and Roos C (2008). Phylogenetic position of the langur genera Semnopithecus and Trachypithecus among Asian colobines, and genus affiliations of their species groups. BMC Evol. Biol. 8: 58. 
Page SL, Chiu C and Goodman M (1999). Molecular phylogeny of Old World monkeys (Cercopithecidae) as inferred from gamma-globin DNA sequences. Mol. Phylogenet. Evol. 13: 348-359.

Peng YZ, Ye ZZ and Pan RL (1988). The classification and phylogeny of snub-nosed monkeys based on gross morphological characters. Zool. Res. 9: 239-247.

Ramharack R and Deeley RG (1987). Structure and evolution of primate cytochrome c oxidase subunit II gene. J. Biol. Chem. 262: 14014-14021.

Roos C, Nadler T and Walter L (2008). Mitochondrial phylogeny, taxonomy and biogeography of the silvered langur species group (Trachypithecus cristatus). Mol. Phylogenet. Evol. 47: 629-636.

Ruvolo M, Disotell TR, Allard MW, Brown WM, et al. (1991). Resolution of the African hominoid trichotomy by use of a mitochondrial gene sequence. Proc. Natl. Acad. Sci. U. S. A. 88: 1570-1574.

Ruvolo M, Zehr S, von Dornum M, Pan D, et al. (1993). Mitochondrial COII sequences and modern human origins. Mol. Biol. Evol. 10: 1115-1135.

Sena L, Vallinoto M, Sampaio I, Schneider H, et al. (2002). Mitochondrial COII gene sequences provide new insights into the phylogeny of marmoset species groups (Callitrichidae, Primates). Folia Primatol. 73: 240-251.

Shahrom AW, Lim LS, Md-Zain BM, Mahani MC, et al. (2005). 2-D Facial reconstruction (when skull is not available) using mitochondrial DNA (MTDNA) phylogeny tree and image morphing techniques: a preliminary study. Int. $J$. Med. Toxicol. Legal Med. 8: 1-5.

Shevchuk NA and Allard MW (2001). Sources of incongruence among mammalian mitochondrial sequences: COII, COIII, and ND6 genes are main contributors. Mol. Phylogenet. Evol. 21: 43-54.

Swofford DL (2002). Phylogenetic Analysis Using Parsimony (and Other Methods). Version 4.0 Beta. Sinauer Associates, Sunderland.

Vun VF (2007). Filogenetik molekul genus Presbytis di Malaysia berdasarkan gen mitokondria Cyt $b$ dan 12S rRNA. MSc thesis, Universiti Kebangsaan Malaysia, Bunge. 